\title{
Hardness and Surface Roughness of Enamel and Base Layers of Resin Denture Teeth after Long-term repeated Chemical Disinfection
}

\author{
${ }^{1}$ Karin Hermana Neppelenbroek, ${ }^{2}$ Luciana Ayumi Kurokawa, ${ }^{3}$ Andréa Lemos Falcão Procópio, ${ }^{4}$ Thiago Amadei Pegoraro \\ ${ }^{5}$ Juliana Hotta, ${ }^{6}$ Jozely Francisca Mello Lima, ${ }^{7}$ Vanessa Migliorini Urban
}

\begin{abstract}
Aim: To evaluate the effect of successive cycles of disinfection in different denture cleansers on the surface roughness and the Vickers hardness of two layers of acrylic resin (base-BL and enamel-EL) of two commercial cross-linked artificial teeth.

Materials and methods: The occlusal surfaces of 60 acrylic resin denture posterior teeth (Trilux-TLX and SR Orthosit PE-SRO) embedded in autopolymerizing acrylic resin were ground flat with 1200-grit silicon carbide paper. Specimens were stored in distilled water at $37^{\circ} \mathrm{C}$ and then submitted to the microhardness $(\mathrm{VHN})$ and roughness $(\mu \mathrm{m})$ tests. Specimens were stored in distilled water at $37^{\circ} \mathrm{C}$ for 90 days and submitted to 720 disinfection cycles in sodium hypochlorite at $0.5 \%, 30 \%$ vinegar solution or distilled water (control). Afterward, microhardness and roughness tests were again performed. Data were analyzed using two-way ANOVA and Tukey's test $(\alpha=0.05)$.
\end{abstract}

Results: Hypochlorite immersion decreased the hardness of $\mathrm{BL}$ and $\mathrm{EL}$ of SRO teeth, with an average reduction of $10.11 \%$ $(p<0.008)$. TLX teeth demonstrated a hardness reduction of $28.96 \%$ of both layers for all solutions including water $(p<0.0000)$. The roughness of both teeth was not affected by denture cleansers $(p>0.37)$.

Conclusion: Hypochlorite promoted deleterious effects on the hardness of both layers of the artificial teeth tested. Immersion in vinegar and water also resulted in reduction of hardness of TLX teeth.

Clinical significance: The surface hardness of the different layers of cross-linked artificial teeth can be altered by daily disinfection in denture cleansers commonly indicated for removable dentures.

Keywords: Laboratory research, Artificial tooth, Hardness, Disinfectants, Surface properties, Polymers.

How to cite this article: Neppelenbroek $\mathrm{KH}$, Kurokawa LA, Procópio ALF, Pegoraro TA, Hotta J, Lima JFM, Urban VM.

\section{1-3,5,6 Department of Prosthodontics, Bauru School of Dentistry University of São Paulo, São Paulo, Brazil \\ ${ }^{4}$ Department of Prosthodontics, Sagrado Coração University São Paulo, Brazil \\ ${ }^{7}$ Department of Dentistry, Ponta Grossa State University Paraná, Brazil}

Corresponding Author: Karin Hermana Neppelenbroek Assistant Professor, Department of Prosthodontics, Bauru School of Dentistry, University of São Paulo, São Paulo, Brazil Phone: 551432358245, e-mail: khnepp@yahoo.com.br
Hardness and Surface Roughness of Enamel and Base Layers of Resin Denture Teeth after Long-term repeated Chemical Disinfection. J Contemp Dent Pract 2015;16(1):54-60.

Source of support: Nil

Conflict of interest: None

\section{INTRODUCTION}

The wear of artificial posterior teeth of acrylic resin dentures can cause occlusal changes, reduction in the vertical dimension of occlusion, loss of masticatory efficiency and overload of supportive tissues by increasing horizontal stresses. ${ }^{1}$ Such wear is influenced by factors such as the intensity and direction of the masticatory forces, abrasiveness of the external environment, salivary $\mathrm{pH}$ and flow, antagonistic dentition, diet, parafunctional habits, poor or excessive hygiene and material of the artificial teeth. ${ }^{2}$ In order to improve the resistance to abrasion and wear, acrylic artificial teeth have been reinforced with the addition of monomers, pressed on different layers and manufactured using technologies, such as polymethyl methacrylate (PMMA) with an interpenetrating polymer network (IPN) or modified by microfilled composite resin. . $^{3,4}$

Inadequate cleaning of prostheses promotes the accumulation and adhesion of biofilm, resulting in unpleasant odor, wear of artificial teeth and denture base and development of pathologies, specially Candidarelated denture stomatitis. ${ }^{5}$ Despite that most patients sanitize their dentures by manual brushing, ${ }^{6}$ such method when used alone has been considered one of the least efficient for biofilm control. ${ }^{7}$ The brushing method requires manual dexterity and visual acuity, which are commonly compromised in elderly people. In addition, the microorganisms embedded in the biofilm become partially protected by the shear forces of the toothbrush. ${ }^{8}$ The irregularities and porosities presented in the acrylic bases also favor the penetration of microorganisms. This raises difficulties in cleaning them exclusively by brushing, and so the prostheses can become a source of infection and reinfection of supporting tissues. ${ }^{9}$

Therefore, for biofilm control, prosthetic removable dentures must be disinfected not only on their surface, 
but also in depth, which can be obtained by manual brushing associated with daily immersion in cleaning agents. Due to the ease of acquisition and low cost, homemade solutions are often adopted by patients who perform a chemical method to clean their removable acrylic dentures..$^{10}$ Alkaline hypochlorite solutions, which are widely used in homemade form by removable denture users, have the ability to dissolve mucin and other organic components, making them highly effective at removing light stains, and also possess bactericidal and fungicide action. ${ }^{11}$ Homemade solutions of vinegar (acetic acid) have been shown to be effective in inhibiting C. albicans both in vitro ${ }^{12}$ and in vivo, ${ }^{13}$ with the advantages of being biodegradable and not presenting risks to the handler.

The nightly immersion of removable dentures in cleaning agents, such as homemade solutions, entails numerous disinfection processes during their shelf life. Consequently, it is ideal that the chemical agent be compatible with the denture base resins and artificial teeth, not interfering with its structure after long-term disinfection procedures. ${ }^{4}$ It has been reported that chemical solutions such as glutaraldehyde, chlorhexidine, alcohols, phenols, alkaline peroxides and hypochlorite can promote deleterious effects to the properties of denture base resins ${ }^{14-16}$ and artificial acrylic teeth. ${ }^{4,17-18}$ According to Shen et al, ${ }^{19}$ certain components of the chemical solutions can penetrate the acrylic resin of denture bases and result in a dissolution surface, changing their morphology. The results of these changes are dependent on the type and concentration of the cleaning agent as well as the immersion time.

It has been shown that indentation by Vickers diamond is a valid method for evaluation of wear resistance, viscoelasticity and other properties of rigid polymers, being the mechanical indicator most commonly evaluated for artificial teeth. ${ }^{20-21}$ Another important surface property is the roughness of the removable denture material, which is directly or indirectly associated with factors such as retention, resistance to staining, microbial adhesion, health of oral tissues and patient comfort. ${ }^{22-23}$

When evaluating surface properties of reinforced artificial teeth, it is important to consider the different layers of acrylic resin that compose them. The outer layer (enamel) of these polymers is more propitious to the effects of wear, considering the stresses inherent to the masticatory cycle and occlusal adjustment procedures that can lead to exposure of at least one of its inner (base) acrylic layers. ${ }^{24-25}$ Loyaga-Rendon et $\mathrm{al}^{24}$ observed that the Vickers hardness of base layers of some commercial reinforced acrylic teeth was significantly lower than the enamel layer with a difference of up to $29.2 \mathrm{VHN}$ among them.
Little information is available in the relevant literature regarding the effect of prolonged immersion in cleaning agents on the properties of artificial acrylic teeth. ${ }^{4,18,26-27}$ Furthermore, there are no studies available on surface properties of hardness and roughness of the different layers that compose acrylic resin artificial teeth following successive cycles of disinfection in chemical agents. Considering the previous aspects, the present study aimed to evaluate the effect of prolonged immersion in denture cleaning agents on the Vickers hardness and surface roughness of enamel and base layers of reinforced acrylic resin artificial teeth. The hypothesis tested was that the surface properties evaluated on different layers of reinforced acrylic resin artificial teeth would be affected by different chemical agents.

\section{MATERIALS AND METHODS}

Sixty reinforced acrylic artificial teeth (first molar, color A2) of two commercial trademarks were used: Trilux (TLX), an IPN resin composed of copolymer of polymethyl methacrylate, ethylene glycol dimethacrylate (EDMA) (Dental Vipi Ltda., Pirassununga, SP, Brazil) and SR Orthosit EP (SRO), composed of urethane dimethacrylate (UDMA) resin reinforced by inorganic fillers (Ivoclar Vivadent, Schaan, Liechtenstein). Two homemade solutions commonly used as cleaning agents were selected: 30\% vinegar solution (alcohol vinegar; Castello foods, Jundiaí, SP, Brazil) and sodium hypochlorite at 0.5\% (Plus Virex; Johnson Diversey Sturtevant, WI, USA).

The molars were included in polyvinyl chloride tubes $(10 \times 17 \mathrm{~mm})$ with colorless self-curing acrylic resin (Vipi Cril; Dental Vipi Ltda., Pirassununga, SP, Brazil), with the mesial surface facing up and toward the level of the top edge of the tubes. After resin polymerization, the occlusal surfaces of the artificial teeth were ground until they were flat and polished, thus exposing the base (BL) and enamel (EL) layers. Grounded occlusal surfaces were polished using 600-, 800-, 1000- and 1200-grit silicon carbide paper discs and felt wheels impregnated with polishing paste (Opal L; Renfert $\mathrm{GmbH}$, Hilzingen, Germany). The specimens were then stored in dark containers with distilled water at $37^{\circ} \mathrm{C}$ (MA 0324; Marconi Laboratory Equipment Ltda., Piracicaba, SP, Brazil) for 24 $h^{18,27}$ and then submitted to the initial tests of hardness and roughness.

The Vickers hardness test was performed using a microhardness indentator machine (Shimadzu HMV2000; Shimadzu Corp., Kyoto, Japan) with a load of $100 \mathrm{~g}$ for $15 \mathrm{~s}$, and the readings of indent data conducted through a software (Cams-Win; New Age Industries Inc., Southampton, PA, USA). For that, BL and EL of the 
artificial teeth specimens were marked in three equal areas. Five indentations were performed at different sections and areas on each specimen, and the mean value was calculated. A Vickers hardness number (VHN) was then calculated for each specimen, and the average value was determined to provide an overall representative mean value of both types of teeth prior to immersion in denture cleansers.

The roughness was measured using a calibrated roughness meter (Hommel Tester Basic T 1000; Hommelwerke $\mathrm{GmbH}$, Schwenningem, Germany) with a cutoff of $0.8 \mathrm{~mm}$ and speed of $0.5 \mathrm{~mm} / \mathrm{s}$, adding up to the measurement path of $2.4 \mathrm{~mm}$. Three measurements of surface roughness were performed in each section and area of both teeth layers, and the mean value (Ra) represented each specimen.

After the initial measurements of hardness and roughness, 10 specimens of each commercial brand of artificial teeth were individually immersed in sodium hypochlorite at $0.5 \%$ for 15 minutes, $30 \%$ vinegar solution for 30 minutes or distilled water (control). This process was repeated eight times a day for a period of 90 days, totaling 720 cycles, which is the equivalent of 2 years of cleaning procedure. ${ }^{27}$ After each cycle, the specimens were rinsed in running water for 1 minute and stored in distilled water at $37^{\circ} \mathrm{C}$. The cleaning agent was replaced at every immersion and distilled water was replaced daily, simulating clinical conditions. After all cycles of disinfection were completed, all specimens were submitted again to the roughness and hardness tests. Before the tests, each specimen was washed in distilled water and dried with absorbent paper. ${ }^{4,28}$

Hardness and roughness values of the both teeth brands (BL and EL) were statistically analyzed by two-way ANOVA ('layer' and 'solution') and the Tukey test $(\alpha=0.05)$. Post hoc power analysis was performed for statistical analysis of hardness and roughness data using personal statistical software (IBM SPSS Statistics 19; SPSS Inc., IBM, Armonk, NY, USA).

\section{RESULTS}

For the number of specimens used $(n=10)$, the study was adequately powered for both analyzed factors 'layer' and 'solution' (over 99\%; $\alpha=0.05$ ) regarding hardness and roughness analyses for both teeth brands (BL and EL).

\section{Vickers Hardness}

Vickers hardness mean values of BL and EL of both SRO and TLX teeth for the denture cleansers tested are exposed in the Table 1.

For SRO teeth, it can be observed in the Table 1 that no significant difference in the BL hardness values was found between the study groups before immersion (initial) in the solutions ( $p>0.08$ ). This situation could also be observed with the initial hardness values of EL for SRO teeth $(p>0.09)$. For these teeth, the only solution that resulted in significant reduction in hardness values was sodium hypochlorite, regardless of the evaluated layer $(p<0.008)$. When comparing the different layers of SRO teeth, it was possible to verify that BL demonstrated significantly higher hardness values than EL in all experimental conditions $(\mathrm{p}<0.005)$ (Table 1$)$.

As seen in the Table 1, no significant difference was observed between the hardness values presented by both layers of TLX teeth before immersion (initial) in all tested solutions ( $p>0.088)$. Table 1 shows a significant reduction in the hardness average of both layers of TLX teeth after successive cycles of disinfection in the two denture cleansers and after prolonged immersion in water $(p<0.0000)$. When comparing the different layers of TLX teeth, it was possible to observe that there was no statistically significant difference in the average hardness for all experimental conditions ( $p<0.095)$ (Table 1).

Table 1: Vickers hardness means $(\mathrm{VHN}) \pm$ standard deviations for the study groups

\begin{tabular}{llllll}
\hline & & & \multicolumn{2}{c}{ Solution } \\
\cline { 3 - 6 } Artificial teeth & Layer & Period & Hypochlorite & Vinegar & Water \\
\hline SRO & $\mathrm{BL}$ & Initial & $31.03 \pm 1.37 \mathrm{Aa}$ & $30.95 \pm 1.35 \mathrm{Aa}$ & $30.63 \pm 1.01 \mathrm{Aa}$ \\
& & Final & $27.81 \pm 0.70 \mathrm{Bb}$ & $30.40 \pm 1.58 \mathrm{Aa}$ & $30.63 \pm 2.13 \mathrm{Aa}$ \\
& $\mathrm{EL}$ & Initial & $22.63 \pm 1.68 \mathrm{Aa}$ & $24.33 \pm 3.11 \mathrm{Aa}$ & $24.74 \pm 3.08 \mathrm{Aa}$ \\
& & Final & $20.42 \pm 1.26 \mathrm{Bb}$ & $22.75 \pm 2.77 \mathrm{Aa}$ & $24.01 \pm 3.53 \mathrm{Aa}$ \\
TLX & $\mathrm{BL}$ & Initial & $21.29 \pm 0.65 \mathrm{Aa}$ & $20.67 \pm 0.66 \mathrm{Aa}$ & $20.35 \pm 0.62 \mathrm{Aa}$ \\
& & Final & $19.13 \pm 0.49 \mathrm{Ba}$ & $18.66 \pm 0.36 \mathrm{Ba}$ & $18.58 \pm 0.61 \mathrm{Ba}$ \\
& $\mathrm{EL}$ & Initial & $20.92 \pm 0.30 \mathrm{Aa}$ & $20.36 \pm 0.48 \mathrm{Aa}$ & $21.08 \pm 1.58 \mathrm{Aa}$ \\
& & Final & $18.21 \pm 0.16 \mathrm{Ba}$ & $18.47 \pm 0.41 \mathrm{Ba}$ & $18.51 \pm 0.25 \mathrm{Ba}$ \\
\hline
\end{tabular}

Vertically, for each layer of each artificial tooth, different capital letters indicate significant differences between the periods for the same solution $(p<0.05)$. Horizontally, for each layer of each artificial tooth, different lowercase letters indicate significant differences among solutions within the same period $(p<0.05)$. For the same tooth brand in the same solution and period, means \pm SD connected by vertical bars are significantly different $(p<0.05)$ between the layers 


\section{Roughness}

The surface roughness mean values of BL and EL of both teeth brands for the tested denture cleansers are exposed in the Table 2.

There was no significant difference between the roughness values presented by both BL and EL of SRO teeth prior to immersion (initial) in all tested solutions ( $p>0.05)$ (Table 2). For these teeth, no significant difference was observed in roughness of BL and EL after immersion in the denture cleansers, including water ( $p>0.37$ ). The comparison between layers of SRO teeth showed that the initial roughness values of EL were significantly higher compared to those obtained with the BL ( $<$ 0.006) (Table 2).

Table 2 shows that no statistically significant difference was found between the roughness values for both layers of TLX teeth before immersion (initial) ( $p>0.068$ ). The BL and EL roughness of TLX teeth did not change after immersion in all tested cleaning solutions, including water ( $p>0.05)$ (Table 2). When comparing the roughness mean values of the two layers for TLX teeth, no significant difference was observed between them before immersion in all solutions $(\mathrm{p}>0.05)$ (Table 2$)$.

\section{DISCUSSION}

This study evaluated the effect of cleaning agents commonly used for prevention and treatment of denture stomatitis on surface properties of different layers of two commercial cross-linked acrylic resin artificial teeth.

Data obtained in this study partially accepted the hypothesis tested, since under certain conditions the hardness of EL and BL of both teeth were altered by the tested cleaning agents but the roughness remained unaffected after simulating overnight disinfection.

According to the manufacturer, SRO teeth are composed of methyl methacrylate polymeric chains of high molecular weight, cross-linked with each other through network cross-connections. These characteristics result in improvement of the physical properties of the acrylic resin such as lower solubility and color change. ${ }^{29}$ Such improvements could explain, in this study, the strength of the respective teeth at prolonged immersion in the solutions tested, including water. Therefore, the roughness and hardness of both layers of SRO teeth were not changed after successive cycles of disinfection. The exception was made for the BL and EL hardness after immersion in sodium hypochlorite, which resulted in an average reduction of $10.11 \%$.

According to the manufacturer, the TLX teeth are composed of methyl methacrylate polymeric chains of high molecular weight, cross-linked with each other via cross-links within another three-dimensional network occupied by a second cross-polymer (IPN resin). With the increase in molecular weight, linear polymer chains grow proportionally due to the possibility of 'double crosslinks'. The two systems ('double cross-links' and IPN) coexist in these teeth and generate inseparable individual polymer chains, ensuring low solubility and increased mechanical resistance of these materials. ${ }^{30,31}$ TLX teeth showed decreased BL and EL hardness after immersion in all the solutions tested, including water. The average values of hardness for TLX teeth ranged from 25.2 VHN (prior to immersion) and 17.9 VHN (after immersion), with an average reduction of $28.96 \%$.

The reduction in hardness after prolonged immersion in the solutions tested for TLX teeth and immersion in sodium hypochlorite for SRO teeth could be attributed to the superficial polymer dissolution by the penetration of components presented in disinfectants. This dissolution becomes increased with higher exposure time to cleaning agent. ${ }^{19}$ In this study, 720 disinfection cycles were used, which is equivalent to a 2-year cleaning of a prosthesis using disinfection agents. ${ }^{27}$ The hardness reduction indicates that there was a cumulative effect by long-term exposure to the solutions tested.

Table 2: Superficial roughness $(\mu \mathrm{m}) \pm$ standard deviations for the study groups

\begin{tabular}{llllll}
\hline & & & \multicolumn{2}{c}{ Solution } \\
\cline { 4 - 6 } Artificial teeth & Layer & Period & Hypochlorite & Vinegar & Water \\
\hline SRO & $\mathrm{BL}$ & Initial & $0.087 \pm 0.045 \mathrm{Aa}$ & $0.079 \pm 0.030 \mathrm{Aa}$ & $0.089 \pm 0.003 \mathrm{Aa}$ \\
& & Final & $0.102 \pm 0.024 \mathrm{Aa}$ & $0.090 \pm 0.051 \mathrm{Aa}$ & $0.096 \pm 0.026 \mathrm{Aa}$ \\
& EL & Initial & $0.114 \pm 0.021 \mathrm{Aa}$ & $0.119 \pm 0.048 \mathrm{Aa}$ & $0.118 \pm 0.058 \mathrm{Aa}$ \\
& & Final & $0.108 \pm 0.028 \mathrm{Aa}$ & $0.110 \pm 0.028 \mathrm{Aa}$ & $0.109 \pm 0.045 \mathrm{Aa}$ \\
TLX & $\mathrm{BL}$ & Initial & $0.116 \pm 0.076 \mathrm{Aa}$ & $0.117 \pm 0.036 \mathrm{Aa}$ & $0.111 \pm 0.041 \mathrm{Aa}$ \\
& & Final & $0.114 \pm 0.057 \mathrm{Aa}$ & $0.113 \pm 0.029 \mathrm{Aa}$ & $0.118 \pm 0.054 \mathrm{Aa}$ \\
& EL & Initial & $0.109 \pm 0.020 \mathrm{Aa}$ & $0.107 \pm 0.024 \mathrm{Aa}$ & $0.110 \pm 0.035 \mathrm{Aa}$ \\
& & Final & $0.116 \pm 0.023 \mathrm{Aa}$ & $0.113 \pm 0.036 \mathrm{Aa}$ & $0.119 \pm 0.030 \mathrm{Aa}$ \\
\hline
\end{tabular}

Vertically, for each layer of each artificial tooth, different capital letters indicate significant differences between the periods for the same solution $(p<0.05)$. Horizontally, for each layer of each artificial tooth, different lowercase letters indicate significant differences among solutions within the same period $(p<0.05)$. For the same tooth in the same solution and period, means \pm SD connected by vertical bars are significantly different $(p<0.05)$ between the layers 
It is likely that due to its composition, SRO teeth presented resistance to hardness change after immersion in water and vinegar. The sodium hypochlorite solution promoted alterations in hardness for both teeth, regardless of the evaluated layer. These results suggest that sodium hypochlorite, even at a low concentration as adopted by this study, presents potentially more harmful effects than the other solutions tested. This alkaline solution, in addition to the antimicrobial capacity, is effective in removing deceased microorganisms of the substrate surface, which may lead to the dissolution of the polymeric structure, ${ }^{32,33}$ resulting in surface changes. The results obtained with the immersion in sodium hypochlorite are in accordance with previous studies, which found greater deleterious effect on hardness of heat-polymerized denture-base resins, ${ }_{15}^{15}$ and artificial acrylic resin teeth. ${ }^{4,17,18}$

In the TLX teeth, the reduction in hardness after immersion in other denture cleansers could be attributed to their own composition, which allowed greater alteration in the polymeric chains. There are no available studies in the relevant literature on the effects of vinegar on the properties of denture base acrylic resin and artificial teeth. In this study, as the hardness of TLX teeth was also reduced after immersion in water, the same explanation could be attributed for both solutions. It is well known that acrylic resin is hydrophilic and absorbs water, ${ }^{34}$ which acts as a plasticizer agent, reducing its hardness by means of micro-crack formations arising from absorption, adsorption and hydrolytic degradation, with cleavage and gradual deterioration of esters links on its structure over time. ${ }^{35}$ According to Braden, ${ }^{34}$ absorption and adsorption of water by polymers are governed by diffusion coefficient (liquid passage from a more to less-saturated medium) and concentration balance (when the saturation of the two mediums equilibrates, ceasing the liquid transport). The absorbed water can be found in two distinct forms: 'free', which occupies free volumes between polymer chains or pores that are created by its polymerization; or 'linked', which is attached to the polymer chain through hydrogen bonds, causing the formation of primary and secondary hydration shells around hydrophilic and ionic endings of the resin matrix. ${ }^{35}$

The plasticizer effect and hydrolytic degradation were more pronounced in the polymeric chains of TLX teeth, which resulted in reduction of hardness after immersion in water and vinegar. These results are in agreement with those obtained by Pavarina et al, ${ }^{26}$ who noted a decrease in hardness of two brands of artificial acrylic teeth after immersion in water. In contrast, Vasconcelos et $\mathrm{a}^{18} \mathrm{did}$ not find a significant reduction of hardness for TLX teeth after three cycles of disinfection in water or $1 \%$ sodium hypochlorite. This difference could be attributed to the reduced number of cycles carried out by the cited authors, in relation to those adopted in this study.

The rougher the acrylic resin artificial teeth, the greater the possibility of accumulation of bacterial biofilm, which leads to loss of brightness and surface degradation of the polymer. ${ }^{36}$ Therefore, it is imperative that a selective polishing of the external surface and artificial teeth of these prostheses be performed after any adjustments that need to be done during a rehabilitation treatment. There are no studies available in the literature that evaluated the effect of prolonged immersion in cleaning agents on the roughness of acrylic teeth. Thus, only a few indirect comparisons could be established.

According to Alves et al, ${ }^{37}$ the penetration of liquids into the polymers can be influenced by roughness. However, in this study, no alteration in surface roughness was detected for the different layers of both acrylic teeth after successive cycles of immersion in the solutions tested. Similar results were obtained by Azevedo et $\mathrm{al}^{38}$ who did not observe significant changes in roughness of three denture base resins after prolonged immersion in cleaning agents. On the contrary, a recent study of Ayaz et $\mathrm{al}^{39}$ demonstrated increased roughness of Acrylux and SRO acrylic teeth after immersion in two solutions based in sodium perborate for 15 minutes. This divergence in relation to the results obtained in this study may be related to the different types of cleaning agents tested. Further studies are needed evaluating additional materials and solutions to confirm this hypothesis.

No information is currently available about roughness for the different layers of acrylic teeth. However, for Vickers hardness, the study of Loyaga-Rendon et $\mathrm{al}^{24}$ showed significantly lower values for the inner layers compared to those of the outer layers of some reinforced acrylic teeth, with a difference of up to $29.2 \mathrm{VHN}$ among them. Unlike those results, in the present research, there was no difference in hardness between both BL and EL for TLX teeth. The same was observed with the roughness results of such teeth. Contrasting the findings of Loyaga-Rendon et al, ${ }^{24}$ the initial BL hardness values ${ }^{24}$ of SRO teeth were significantly greater than those observed for the EL. The initial roughness of EL for these teeth was also higher than that observed for BL. This contradiction was expected since generally greater roughness implies lesser hardness. ${ }^{23}$ To explain the initial results of hardness and roughness obtained between the two layers of the TLX teeth, where there was no alteration - and between the SRO teeth, in which such difference was observed in vitro studies with dynamic wear tests and in vivo studies in removable dentures users are required. It is important to note that the tooth surface properties tested were 
evaluated for both layers since it is expected that the wear of the outer layer of the teeth by use or adjustment procedures results in exposure of their inner layer.

The present study suggests that cleaning agents for removable dentures can cause alterations in Vickers hardness of acrylic reinforced artificial teeth. However, the artificial teeth can suffer various other influences that could not be assessed with the in vitro methodology used in this study. In clinical use, artificial teeth of removable prosthesis may have their surface properties influenced by various dynamic conditions, such as quantity and quality of saliva, hygiene procedures adopted, type of food (consistency), frequency of intake of acidic foods, parafunctional habits, type of artificial tooth, antagonist dentition and occlusal condition, among many others. In addition, only two brands of acrylic teeth and two cleaning solutions were tested. Therefore, the results of the present study should be interpreted with caution.

\section{CONCLUSION}

According to the methodology used and based on the results obtained, it was possible to conclude that:

- Sodium hypochlorite was the only solution that resulted in significant reduction in hardness values of the SRO teeth, regardless of the evaluated layer.

- The BL of SRO teeth presented, respectively, higher hardness and lower roughness in relation to those observed for EL.

- Both layers of the TLX teeth demonstrated hardness reduction, decreasing after successive cycles in the cleaning agents, including water.

- There was no statistically significant difference in hardness and roughness between the BL and EL of TLX teeth.

- There was no difference in roughness for both layers of SRO and TLX teeth after prolonged immersion in the solutions tested, including water.

\section{CLINICAL SIGNIFICANCE}

Daily night immersion of removable prosthesis in denture cleansers is commonly adopted as the method for prevention and treatment of denture stomatitis. Thus, throughout their lifetime, the dentures are exposed to several cycles of disinfection in such solutions, which can result in property changes of denture base resins and acrylic teeth. This study demonstrated that successive cycles of disinfection in homemade solutions for night immersion of removable dentures might negatively affect the surface hardness of the different layers of cross-linked artificial teeth.

\section{ACKNOWLEDGMENTS}

This study was supported by the São Paulo Research Foundation-FAPESP (grants 2009/01040-0 and 2010/ 07788-4). The authors wish to thank Dental Vipi and Ivoclar Vivadent for kindly providing the artificial teeth used in this study.

\section{REFERENCES}

1. Khanna G, Aparna I. Comparison of microhardness of three different types of acrylic artificial denture teeth: an in vitro study. JOFR 2013 Jul-Sep;3(3):181-185.

2. Ogle RE, David LJ, Ortman HR. Clinical wear study of a new tooth material: Part II. J Prosthet Dent 1985 Jul;54(1):67-75.

3. Powers JM, Sakaguchi RL. Craig's Restorative dental materials. 12th ed. Philadelphia: Mosby Elsevier; 2006.

4. Campanha NH, Pavarina AC, Jorge JH, Vergani CE, Machado AL, Giampaolo ET. The effect of long-term disinfection procedures on hardness property of resin denture teeth. Gerodontology 2012 Jun;29(2):571-576.

5. Neill DJ. A study of materials and methods employed in cleaning dentures. Br Dent J 1968;124:107-115.

6. Coelho CM, Sousa YT, Daré AM. Denture-related oral mucosal lesions in a Brazilian school of dentistry. J Oral Rehabil. 2004 Feb;31(2):135-139.

7. Barnabé W, de Mendonça Neto T, Pimenta FC, Pegoraro LF, Scolaro JM. Efficacy of sodium hypochlorite and coconut soap used as disinfecting agents in the reduction of denture stomatitis, Streptococcus mutans and Candida albicans. J Oral Rehabil 2004 May;31(5):453-459.

8. Baena-Monroy T, Moreno-Maldonado V, Franco-Martínez F, Aldape-Barrios B, Quindós G, Sánchez-Vargas LO. Candida albicans, Staphylococcus aureus and Streptococcus mutans colonization in patients wearing dental prosthesis. Med Oral Patol Oral Cir Bucal 2005 Apr 1;10(Suppl 1):27-39.

9. Neppelenbroek KH, Pavarina AC, Palomari Spolidorio DM, Sgavioli Massucato EM, Spolidorio LC, Vergani CE. Effectiveness of microwave disinfection of complete dentures on the treatment of Candida-related denture stomatitis. J Oral Rehabil 2008 Nov;35(11):836-846.

10. Shay K. Denture hygiene: a review and update. J Contemp Dent Pract 2000 Feb 15;1(2):28-41.

11. Abelson DC. Denture plaque and denture cleansers: review of the literature. Gerodontics 1985 Oct;1(5):202-206.

12. Kumar MN, Thippeswamy HM, Raghavendra Swamy KN, Gujjari AK. Efficacy of commercial and household denture cleansers against Candida albicans adherent to acrylic denture base resin: an in vitro study. Indian J Dent Res 2012 Jan-Feb;23(1):39-42.

13. Pinto TM, Neves AC, Leão MV, Jorge AO. Vinegar as an antimicrobial agent for control of Candida spp. in complete denture wearers. J Appl Oral Sci 2008 Nov-Dec;16(6):385-390.

14. Asad T, Watkinson AC, Huggett R. The effects of various disinfectant solutions on the surface hardness of an acrylic resin denture base material. Int J Prosthodont 1993 JanFeb;6(1):9-12.

15. Neppelenbroek KH, Pavarina AC, Vergani CE, Giampaolo ET. Hardness of heat-polymerized acrylic resins after disinfection and long-term water immersion. J Prosthet Dent 2005 Feb;93(2):171-176. 
16. Polyzois GL, Zissis AJ, Yannikakis SA. The effect of glutaraldehyde and microwave disinfection on some properties of acrylic denture resin. Int J Prosthodont 1995 Mar-Apr;8(2):150-154.

17. Pisani MX, Macedo AP, Paranhos Hde F, Silva CH. Effect of experimental Ricinus communis solution for denture cleaning on the properties of acrylic resin teeth. Braz Dent J 2012;23(1):15-21.

18. Vasconcelos LR, Consani RL, Mesquita MF, Sinhoreti MA. Effect of chemical and microwave disinfection on the surface microhardness of acrylic resin denture teeth. J Prosthodont 2013 Jun;22(4):298-303.

19. Shen C, Javid NS, Colaizzi FA. The effect of glutaraldehyde base disinfectants on denture base resins. J Prosthet Dent 1989 May;61(5):583-589.

20. Mahoney E, Holt A, Swain M, Kilpatrick N. The hardness and modulus of elasticity of primary molar teeth: an ultramicro-indentation study. J Dent 2000 Nov;28(8):589-594.

21. Peutzfeldt A, García-Godoy F, Asmussen E. Surface hardness and wear of glass ionomers and compomers. Am J Dent 1997 Feb;10(1):15-17.

22. Nikawa H, Sadamori S, Hamada T, Okuda K. Factors involved in the adherence of Candida albicans and Candida tropicalis to protein adsorbed surfaces. An in vitro study using immobilized protein. Mycopathologia 1992;118(3):139-145.

23. Quirynen M, Bollen CM. The influence of surface roughness and surface-free energy on supra- and subgingival plaque formation in man. A review of the literature. J Clin Periodontol 1995;22(1):1-14.

24. Loyaga-Rendon PG, Takahashi H, Hayakawa I, Iwasaki N. Compositional characteristics and hardness of acrylic and composite resin artificial teeth. J Prosthet Dent 2007;98(2): 141-149.

25. Suwannaroop P, Chaijareenont P, Koottathape N, Takahashi $\mathrm{H}$, Arksornnukit $\mathrm{M}$. In vitro wear resistance, hardness and elastic modulus of artificial denture teeth. Dent Mater J 2011;30(4):461-468.

26. Pavarina AC, Vergani CE, Machado AL, Giampaolo ET, Teraoka MT. The effect of disinfectant solutions on the hardness of acrylic resin denture teeth. J Oral Rehabil 2003 Jul;30(7):749-752.
27. Lira AF, Consani RL, Mesquita MF, Nóbilo MA, Henriques GE. Effect of toothbrushing, chemical disinfection and thermocycling procedures on the surfasse microroughness of denture base acrylic resins. Gerodontology 2012 Jun; 29(2):e891-897.

28. Silva PM, Acosta EJ, Jacobina M, Pinto Lde R, Porto VC. Effect of repeated immersion solution cycles on the color stability of denture tooth acrylic resins. J Appl Oral Sci 2011 Nov-Dec; 19(6):623-627.

29. Satoh Y, Nagai E, Maejima K, Azaki M, Matsuzu R, Matsuzu $\mathrm{M}$, et al. Wear of denture teeth by use of metal plates. Part 2: Abrasive wear of posterior teeth. J Nihon Univ Sch Dent 1992 Mar;34(1):16-27.

30. Coffey JP, Goodkind RJ, DeLong R, Douglas WH. In vitro study of the wear characteristics of natural and artificial teeth. J Prosthet Dent 1985 Aug;54(2):273-280.

31. Ogle RE, David LJ, Ortman HR. Clinical wear study of a new tooth material: Part II. J Prosthet Dent. 1985 Jul;54(1):67-75.

32. Budtz-Jørgensen E. Materials and methods for cleaning dentures. J Prosthet Dent 1979 Dec;42(6):619-623.

33. Jagger DC, Harrison A. Denture cleansing-the best approach. Br Dent J 1995 Jun 10;178(11):413-417.

34. Braden $M$. The absorption of water by acrylic resins and other materials. J. Prosthet. Dent, St. 1964 Mar-Apr;14(2):307-316.

35. Yiu CK, King NM, Pashley DH, Suh BI, Carvalho RM, Carrilho MR, et al. Effect of resin hydrophilicity and water storage on resin strength. Biomaterials 2004 Nov;25(26):5789-5796.

36. Rahal JS, Mesquita MF, Henriques GE, Nóbilo MA. Surface roughness of acrylic resins submitted to mechanical and chemical polishing. J Oral Rehabil 2004 Nov;31(11):1075-1079.

37. Alves PV, Lima Filho RM, Telles E, Bolognese A. Surface roughness of acrylic resins after different curing and polishing techniques. Angle Orthod 2007 May;77(3):528-531.

38. Azevedo A, Machado AL, Vergani CE, Giampaolo ET, Pavarina AC, Magnani R. Effect of disinfectants on the hardness and roughness of reline acrylic resins. J Prosthodont 2006 Jul-Aug;15(4):235-242.

39. Ayaz EA, Altintas SH, Turgut S. Effects of cigarette smoke and denture cleaners on the surface roughness and color stability of different denture teeth. J Prosthet Dent 2014 Aug; 112(2):241-248 